\title{
Soluble CD95 concentrations are increased in patients with severe systemic lupus erythematosus, but not in their first degree relatives
}

\author{
M W van der Linden, T van Lopik, L A Aarden, R G J Westendorp, T W J Huizinga
}

Department of Clinical Epidemiology, Leiden University Medical Centre, The

Netherlands $M W$ van der Linden R G J Westendorp

Department of Rheumatology, Leiden University Medical Centre

T W J Huizinga

Department of Autoimmune Diseases, Central Laboratory of the Blood Transfusion

Service, and

Laboratory for Experimental and Clinical Immunology, Academic Medical Centre, University of

Amsterdam,

Amsterdam, The

Netherlands

$\mathrm{T}$ van Lopik

L A Aarden

Correspondence to: Dr T W J Huizinga, Department of Rheumatology, Building 1, C4-R Leiden University Medical Centre, PO Box 9600, 2300 RC Leiden, The Netherlands

TWJHuizinga@

rheumatology.azl.nl

Accepted 25 July 2000

\begin{abstract}
Objective-Plasma concentrations of soluble CD95 (sCD95) are raised in patients with systemic lupus erythematosus (SLE) before clinical relapses become manifest. Increased sCD95 concentrations may therefore be a familial characteristic that is associated with susceptibility to severe disease. To test this, $\mathrm{SCD} 95$ concentrations were measured in healthy first degree relatives of patients with severe and non-severe SLE.
\end{abstract}

Methods-Seventy seven first degree relatives of 26 patients with severe, and 72 relatives of 25 patients with non-severe lupus were studied. Controls were 42 first degree relatives of 17 patients with chronic cutaneous lupus erythematosus (CCLE) and 63 partners of the patients with their first degree relatives. Severe lupus was defined as both multi-organ disease and cyclophosphamide treatment, non-severe lupus as neither. Organ damage was assessed with the SLICC-ACR index, disease activity with SLEDAI.

Results-Soluble CD95 concentrations in relatives of patients with severe SLE were similar to those in relatives of patients with non-severe SLE, relatives of patients with CCLE, and controls (median (interquartile range) sCD95 concentration 0.59 (0.52-0.66) $v 0.57(0.50-0.63), 0.56(0.51-$ $0.71)$, and $0.55(0.49-0.61) \mathrm{ng} / \mathrm{ml}, \mathrm{p}=0.25$, $\mathrm{p}=0.94$, and $\mathrm{p}=0.17$, respectively). Increased concentrations of $\mathrm{sCD} 95$, however, were found in patients with severe SLE compared with those in patients with non-severe SLE, patients with CCLE, and control relatives $(0.77(0.70-0.97) \quad v \quad 0.60$ $(0.54-0.67), 0.57(0.54-0.71)$, and 0.57 $(0.52-0.63) \mathrm{ng} / \mathrm{ml}$, respectively, $\mathrm{p}<0.001)$. Concentrations of sCD95 were significantly correlated with damage index scores $\left(r_{\mathrm{s}}=0.47, \mathrm{p}<0.01\right)$. Basic and clinical characteristics of patients with SLE, including SLEDAI scores, could not explain these observations.

Conclusion-Soluble CD95 concentrations are associated with severity of the disease and not with susceptibility for severe SLE.

(Ann Rheum Dis 2001;60:237-241)

Systemic lupus erythematosus (SLE) is an autoimmune disease in which genetic factors have an important role. Antinuclear antibodies directed against antigenic components of the cell nucleus, such as nucleosomal antigens, are a key feature of SLE. Autoantibodies are more often present in first degree relatives of patients with SLE than in the general population. ${ }^{1-4}$ This suggests that a strong non-specific humoral autoimmune response is a familial characteristic of SLE. Familial factors are also important in the severity of the disease. ${ }^{5}$

Antigens expressed in apoptotic cells are common targets for autoantibodies, which suggests that abnormalities of apoptosis are an important mechanism underlying autoantibody production and SLE. ${ }^{6}$ Gene transfer studies indicate that a molecule largely responsible for autoantibody production is CD95 (Apo-1, Fas), which is a key molecule in apoptosis regulation. ${ }^{7}$ Moreover, in the MRL-lpr/ lpr mouse model for SLE, autoantibody production is associated with a genetic defect in CD95.

Soluble CD95 (sCD95) molecules are formed as an alternative mRNA splice variant and as a proteolytically cleaved fragment of the transmembrane molecule CD95..$^{910}$ Increased plasma concentrations of sCD95 have been reported in patients with SLE, and baseline plasma concentrations of sCD95 are higher in patients who relapse within six months than in patients who remain clinically quiescent. ${ }^{11}$ Circulating sCD95 levels remain high in these patients at least until six months after relapse (van Lopik, personal communication). This suggests that patients who are prone to clinical relapses have high circulating levels of sCD95 as an inherent patient characteristic which may be genetically determined.

To test whether increased plasma concentrations of sCD95 are a familial characteristic of patients with SLE, we measured sCD95 in first degree relatives of these patients. Partners with their first degree relatives served as controls. Patients with chronic cutaneous lupus erythematosus (CCLE), with their first degree relatives, were studied as a second control group.

\section{Methods}

STUDY GROUP

First degree relatives of patients with severe and non-severe SLE were recruited. After approval by the institutional medical ethics board, patients fulfilling at least four of the American College of Rheumatologists' criteria for $\mathrm{SLE}^{12}$ were identified from the Leiden University Medical Centre Rheumatology Clinic and outpatient clinic. Patients were classified as having severe SLE when treatment indication 
Table 1 Demographic and clinical characteristics of families of patients with systemic lupus erythematosus (SLE), chronic cutaneous lupus erythematosus (CCLE), and controls

\begin{tabular}{|c|c|c|c|c|}
\hline & Severe SLE ${ }^{\star}$ & $\begin{array}{l}\text { Non-severe } \\
S L E^{\star}\end{array}$ & $C C L E$ & Controls \\
\hline Number of families & 26 & 25 & 17 & 21 \\
\hline \multicolumn{5}{|l|}{ Patients } \\
\hline Male/female (n) & $3 / 23$ & $1 / 24$ & $8 / 9$ & - \\
\hline Age (years) & $38(3.4)$ & $41(2.5)$ & $48(2.7)$ & - \\
\hline White/non-white (n) & $18 / 8$ & $24 / 1$ & $17 / 0$ & - \\
\hline Time since diagnosis (years) & $8.0(1.0)$ & $13(1.1)$ & $14(0.9)$ & - \\
\hline Damage score $\dagger$ & $4.9(0.5)$ & $1.2(0.2)$ & - & - \\
\hline Activity score $\ddagger$ & $5.1(1.1)$ & $2.4(0.5)$ & - & - \\
\hline \multicolumn{5}{|l|}{ First degree relatives } \\
\hline Number & 77 & 72 & 42 & 63 \\
\hline Family size & $3.1(0.3)$ & $3.2(0.5)$ & $2.5(0.3)$ & $2.4(0.2)$ \\
\hline Male/female (n) & $33 / 44$ & $33 / 39$ & $15 / 27$ & $30 / 33$ \\
\hline Age (years) & $41(1.9)$ & $47(2.0)$ & $38(2.7)$ & $49(2.1)$ \\
\hline White/non-white (n) & $55 / 22$ & $70 / 2$ & $42 / 0$ & $63 / 0$ \\
\hline
\end{tabular}

Results are shown as means (SEM).

* Severe SLE was defined by treatment with cyclophosphamide and renal/cerebral organ disease; non-severe SLE by 10 years' disease without cyclophosphamide treatment and involvement of at most one of these organ systems (see "Methods").

†Accumulated organ damage was measured by the SLICC/ACR Damage Index.

$\ddagger$ Disease activity at time of blood sampling was measured by SLEDAI.

for cyclophosphamide existed at any time since diagnosis for renal or cerebral disease, or both. Of 26 patients with an indication for cyclophosphamide treatment, three were eventually treated with azathioprine because of fertility concerns. Patients were classified as having non-severe SLE when they had never been treated with cyclophosphamide and had been free of multi-organ disease for at least 10 years. Patients who could be classified according to the criteria mentioned above were interviewed for eligibility and their first degree relatives (parents, brothers and sisters, and/or children) were also invited. One hundred and forty nine first degree relatives free of disease belonging to 26 patients with severe SLE and 25 patients with non-severe SLE participated. Accumulated organ damage was measured with the SLICC/ACR Damage Index, and disease activity with SLE the Disease Activity Index (SLEDAI)..$^{13} 14$

If the patients agreed, their partners and the first degree relatives of the partners were invited to participate as controls. Twenty one partners and 42 of their first degree relatives were enrolled in a similar procedure as described above. As a second control group families of patients with histopathologically confirmed CCLE who had negative antinuclear factor serology on initial diagnosis were identified. All patients with CCLE had a disease course of at least 10 years to ensure that generalised disease had not developed. Forty two healthy first degree relatives belonging to 17 patients with CCLE were enrolled.

SOLUBLE CD95

The combination of CLB-CD $95 / 2$ and CLBCD95/6 monoclonal antibodies directed against the extracellular portion of Fas was used. Microtitre plates (Nunc, Denmark) were coated with $100 \mu \mathrm{l} /$ well CLB-CD95/2 in $0.1 \mathrm{M}$ $\mathrm{NaHCO}_{3} \mathrm{Na}_{2} \mathrm{CO}_{3}$ buffer ( $\mathrm{pH} 9.6$ ) overnight at room temperature. Coated plates were washed five times with phosphate buffered saline (PBS)/Tween-20 (PBST). Samples and standards were diluted in a high performance enzyme linked imunosorbent assay (ELISA) buffer (CLB, Asterdam, The Netherlands) and
$100 \mu 1$ of each sample dilution was added to the plate. To each sample dilution, $10 \mu \mathrm{l}$ of a 10 $\mu \mathrm{g} / \mathrm{ml}$ solution of biotin coupled CLB-CD95/6 was added and the plate was incubated for two hours at room temperature. After five washes with PBST $100 \mu \mathrm{l}$ of streptavidine-poly horseradish peroxidase (CLB, Amsterdam, The Netherlands) diluted 1:10 000 in PBS containing $2 \%$ whole milk was incubated for 30 minutes at room temperature. The plates were washed five times with PBST and developed with $100 \mu$ l substrate solution $(0.1 \mathrm{mg} / \mathrm{ml}$ 3,5,3',5'-tetramethylbenzidine, Merck, Darmstadt, Germany) containing $0.003 \% \mathrm{H}_{2} \mathrm{O}_{2}$ in $0.11 \mathrm{M} \mathrm{NaAc}(\mathrm{pH} \mathrm{5.5)}$ for 10 minutes. The enzyme reaction was stopped with $100 \mu \mathrm{l} 2 \mathrm{M}$ $\mathrm{H}_{2} \mathrm{SO}_{4}$. Plates were read at $450 \mathrm{~nm}$ in a titertek Multiskan reader (Labsystems Multiskan Multisoft, Helsinki, Finland). ${ }^{15}$

\section{STATISTICAL ANALYSIS}

Comparisons between multiple groups were first tested with the Kruskal-Wallis test to detect differences between groups. If a difference was present, Mann-Whitney's test was then used to identify groups responsible for the difference. Spearman's coefficient was used to test correlation between variables. These nonparametric tests do not make assumptions about the distribution of the data. In some analyses, adjustment for confounding variables was performed using linear regression. In these analyses the confounding variable (age, serum creatinine concentration) was introduced as a covariate in the regression equation that models concentration of sCD95 according to group - that is, patients, relatives of patients, or controls.

\section{Results}

DEMOGRAPHIC AND CLINICAL CHARACTERISTICS OF PATIENTS, FIRST DEGREE RELATIVES, AND CONTROLS

Table 1 shows the demographic and clinical characteristics of those studied. Families of patients with CCLE and control families were all white, but nine families of patients with SLE were not. Patients with severe SLE, their first degree relatives, and first degree relatives of patients with CCLE were younger than the controls. More of them were female than among the controls. As a result of patient classification, organ damage and disease activity were higher in the patients with severe SLE than in those with non-severe SLE. Among the 20 patients with severe SLE who were not currently treated with cyclophosphamide at the time of blood sampling or less than six months before, $14(70 \%)$ had active disease necessitating treatment with steroids either alone or in combination with azathioprine. Organ damage in these 20 patients was similar to that in the six patients with severe SLE who were currently being treated with cyclophosphamide (data not shown).

Among relatives of patients with SLE, there was no difference in sCD95 concentration between white and non-white subjects (median (25th centile-75th centile) sCD95 concentration $0.58(0.51-0.64) \quad v \quad 0.58(0.50-0.66)$ 
Table 2 Plasma concentration of sCD95 in first degree relatives of patients with systemic lupus erythematosus (SLE), first degree relatives of patients with chronic cutaneous lupus erythematosus (CCLE), and controls

\begin{tabular}{|c|c|c|c|}
\hline & $\begin{array}{l}\text { Relatives of patients with } \\
\text { SLE }\end{array}$ & $\begin{array}{l}\text { Relatives of patients with } \\
\text { CCLE }\end{array}$ & $\begin{array}{l}\text { Relatives of } \\
\text { partners }\end{array}$ \\
\hline $\begin{array}{l}\text { Number } \\
\text { Soluble CD95 (ng/ml) }\end{array}$ & 149 & 42 & 42 \\
\hline $\begin{array}{l}\text { Median } \\
\text { (Interquartile range) }\end{array}$ & $\begin{array}{l}0.58 \\
(0.51-0.65)\end{array}$ & $\begin{array}{l}0.56 \\
(0.51-0.71)\end{array}$ & $\begin{array}{l}0.57 \\
(0.52-0.63)\end{array}$ \\
\hline
\end{tabular}

No statistically significant differences in SCD95 concentration between these groups were found ( $\mathrm{p}>0.4$, Mann-Whitney tests).

Table 3 Plasma concentration of sCD95 in patients with systemic lupus erythematosus (SLE), patients with chronic cutaneous lupus erythematosus (CCLE), and controls

\begin{tabular}{|c|c|c|c|c|c|}
\hline & Severe SLE† & $\begin{array}{l}\text { Non-severe } \\
\text { SLE† }\end{array}$ & CCLE & $\begin{array}{l}\text { Partners of } \\
\text { patients }\end{array}$ & $\begin{array}{l}\text { Relatives of } \\
\text { partners }\end{array}$ \\
\hline $\begin{array}{l}\text { Number } \\
\text { Soluble CD95 (ng/ml) }\end{array}$ & 26 & 25 & 17 & 21 & 42 \\
\hline $\begin{array}{l}\text { Median } \\
\text { (Interquartile range) }\end{array}$ & $\begin{array}{l}0.77^{\star \star} \\
(0.70-0.97)\end{array}$ & $\begin{array}{l}0.60^{\star} \\
(0.54-0.67)\end{array}$ & $\begin{array}{l}0.57 \\
(0.54-0.71)\end{array}$ & $\begin{array}{l}0.53 \\
(0.46-0.59)\end{array}$ & $\begin{array}{l}0.57 \\
(0.52-0.63)\end{array}$ \\
\hline
\end{tabular}

${ }^{\star} \mathrm{p}=0.008$ compared with partners, $\mathrm{p}=0.324$ compared with relatives of partners.

${ }^{\star} \star \mathrm{p}<0.001$ compared with patients with non-severe SLE, patients with CCLE, partners, and relatives of partners.

†Severe SLE was defined by treatment with cyclophosphamide and renal/cerebral organ disease; non-severe SLE by 10 years' disease without cyclophosphamide treatment and involvement of at most one of these organ systems (see "Methods").

$\mathrm{ng} / \mathrm{ml}, \mathrm{p}=0.95)$. Among the patients, there was also no such difference (data not shown). There was a moderate correlation between age and $\mathrm{sCD} 95$ concentrations $\left(r_{s}=0.4, \mathrm{p}=0.002\right.$, among control subjects). No association between sCD95 concentrations and sex was found (concentration of $\mathrm{sCD} 95$ in male controls $0.54(0.50-0.63) v 0.57(0.46-0.61)$ $\mathrm{ng} / \mathrm{ml}$ in female controls, $\mathrm{p}=0.48)$.

SOLUBLE CD95 IN FAMILIES OF PATIENTS WITH SLE, FAMILIES OF PATIENTS WITH CCLE, AND CONTROLS

To examine whether an increased sCD95 concentration is a familial susceptibility factor for SLE and CCLE, plasma sCD95 concentrations were measured in first degree relatives of the patients and controls. Table 2 indicates plasma concentrations of sCD95 in first degree relatives of patients with SLE, first degree relatives of patients with CCLE, and healthy controls. To avoid a possible influence of shared environment between patients and partner controls, only the first degree relatives of the partners are presented in table 2 . There was no difference between the sCD95 concentrations in first degree relatives of patients with SLE and the first degree relatives of the partners $(0.58(0.51-0.65)$ v $0.57(0.52-0.63) \mathrm{ng} / \mathrm{ml}$, $\mathrm{p}=0.85)$.

SOLUBLE CD95 IN RELATION TO SEVERITY OF SLE It was first investigated whether increased plasma concentrations of sCD95 are a familial disease characteristic of severe SLE, as defined by treatment with cyclophosphamide and renal/cerebral organ disease. Soluble CD95 concentrations in first degree relatives of patients with severe SLE were similar to those in first degree relatives of patients with non-severe SLE (0.59 (0.52-0.66) $v 0.57$ (0.50-0.63) $\mathrm{ng} / \mathrm{ml}, \mathrm{p}=0.25)$. Soluble CD95 concentrations were also similar in first degree relatives of patients with severe SLE and in first degree relatives of patients with CCLE (0.59
$(0.52-0.66) \quad v \quad 0.56 \quad(0.51-0.71) \quad \mathrm{ng} / \mathrm{ml}$, $\mathrm{p}=0.94)$. When adjustment for the effect of age was made, similar results were obtained (linear regression, data not shown).

It was then investigated whether increased plasma concentrations of sCD95 are a nonfamilial disease characteristic of disease severity, as defined by treatment with cyclophosphamide and renal/cerebral organ disease. Therefore plasma concentrations of sCD95 were measured in patients with severe and non-severe SLE. Plasma concentrations of sCD95 were higher in patients with SLE than in their own first degree relatives $(0.69$ $(0.58-0.71)$ v $0.58 \quad(0.51-0.65) \quad \mathrm{ng} / \mathrm{ml}$, $\mathrm{p}<0.001)$. Table 3 compares plasma concentrations of sCD95 in patients with severe and non-severe SLE with those in patients with CCLE and controls. Increased plasma concentrations of sCD95 in patients with severe SLE compared with those in patients with nonsevere SLE, patients with CCLE, and controls were seen (Kruskal-Wallis and Mann-Whitney tests, $\mathrm{p}<0.001)$. This association between sCD95 concentration and disease severity in patients was unaffected after adjustment for the effect of age $(p<0.001)$. A trend towards increased sCD95 concentrations in patients with non-severe SLE when compared with controls was seen $(p=0.07)$. After adjustment for the effect of age this trend was stronger $(p=0.02)$. No significant difference in sCD95 concentration was found between patients with CCLE and controls $(\mathrm{p}=0.18)$.

Disease activity may have an influence on increased sCD95 concentrations in patients with severe and non-severe SLE. Indeed, sCD95 and SLEDAI values were significantly correlated (Spearman's correlation coefficient, $\left.r_{\mathrm{s}}=0.40, \mathrm{p}<0.01\right)$. Therefore, the comparison of sCD95 concentrations in patients with severe SLE with those in patients with non-severe SLE, as presented in table 3, was adjusted for SLEDAI scores. The results were similar (data not shown). In line with these analyses, a positive correlation between sCD95 concentration and organ damage, as measured by SLICC/ ACR Damage Index values, was found. This remained essentially unchanged after adjustment for SLEDAI scores (regression, $r_{\mathrm{s}}=0.47$, $\mathrm{p}<0.001$, and $r_{\mathrm{s}}=0.30, \mathrm{p}=0.016$, respectively).

Specific disease manifestations associated with high SLICC/ACR Damage Index values were SLE nephritis and neuropsychiatric SLE. Higher sCD95 concentrations were found in patients with nephritis than in those without (0.72 (0.68-0.94) v $0.62(0.56-0.74) \mathrm{ng} / \mathrm{ml}$, $\mathrm{p}=0.003)$. Also, higher sCD95 concentrations were found in patients with neuropsychiatric SLE than in those without $(0.77(0.69-0.98) v$ $0.66(0.58-0.75) \mathrm{ng} / \mathrm{ml}, \mathrm{p}=0.014)$. However, these differences disappeared when patients with severe SLE and patients with non-severe SLE were analysed separately (patients with severe SLE: nephritis $v$ non-nephritis, $\mathrm{p}=0.324$, neuropsychiatric SLE $v$ nonneuropsychiatric SLE, $\mathrm{p}=0.71$; patients with non-severe SLE: nephritis $v$ non-nephritis, $\mathrm{p}=0.58$, neuropsychiatric SLE $v$ nonneuropsychiatric SLE, $\mathrm{p}=0.89$ ). 
Increased sCD95 concentrations in patients with severe SLE may be explained by renal function impairment. However, analysis of sCD95 concentrations adjusted for serum creatinine concentrations yielded results similar to the unadjusted analysis $(\mathrm{p}<0.001)$. Also, the combined effects of age and creatinine concentrations did not explain the increase in SCD95 concentrations in patients with severe SLE compared with patients with non-severe SLE $(\mathrm{p}=0.001)$.

To control for a possible influence of current treatment of patients with cytotoxic drugs (cyclophosphamide, prednisone, and/or azathioprine) the analysis was restricted to patients not currently ( $<6$ months) using these drugs. The plasma concentration of sCD95 in patients with severe SLE without current cytotoxic treatment $(n=20)$ was higher than in patients with non-severe SLE without current cytotoxic treatment (such as azathioprine or prednisone $)(\mathrm{n}=17)(0.76(0.65-0.92) v 0.60$ (0.53-0.67) $\mathrm{ng} / \mathrm{ml}, \mathrm{p}=0.012$ ).

\section{Discussion}

In this study no evidence for an increased concentration of sCD95 in first degree relatives of patients with SLE was found. Nevertheless, increased concentrations of sCD95 in patients with severe SLE were found. This suggests that an increase in sCD95 concentrations is associated with severity of the disease, and not with familial susceptibility for SLE.

Soluble CD95 concentrations were highest in patients with severe SLE, as defined by treatment with cyclophosphamide and renal/ cerebral organ disease, and a correlation between sCD95 and the SLICC/ACR Damage Index was found. Therefore, an increased concentration of sCD95 is interpreted as a characteristic of severe SLE. This is in agreement with a transverse study that showed a correlation between sCD95 concentrations and the SLICC/ACR Damage Index values, ${ }^{16}$ and also with our transverse and longitudinal studies of a different set of patients with SLE that showed an increase in SCD95 concentrations even before clinical exacerbations become manifest. ${ }^{11}{ }^{15}$ Nevertheless, we found an association between sCD95 concentrations and current disease activity as measured by the SLEDAI. This association is in line with earlier reports, ${ }^{15}{ }^{17}$ though other groups found normal sCD95 concentrations in patients with SLE, probably owing to differences in assay characteristics. ${ }^{18-21}$ It is noteworthy that disease activity in itself cannot explain the association of sCD95 with severity and organ damage in SLE.

To avoid misclassification of patients with severe SLE into the non-severe SLE group the criterion of 10 years' disease without involvement of more than one of the renal and cerebral organ systems, and without cyclophosphamide treatment was used. In a 10 year follow up study Ginzler et al showed that of $29 \%$ of patients with SLE who eventually develop lethal complications, the vast majority do so within the first five years after diagnosis. ${ }^{22}$
Increased concentrations of sCD95 may be explained by cytotoxic drugs, which are known from experimental settings to induce apoptosis. ${ }^{23}$ This may subsequently lead to the release of sCD95 from apoptotic cell fragments. However, an analysis restricted to those without cytotoxic drugs excludes the substantial influence of drugs.

Several mechanisms of action of sCD95 in the pathogenesis of severe SLE may be at play. Soluble CD95 may block the action of the CD95 ligand (CD95L), thereby preventing CD95-CD95L interaction and apoptosis initiation. $^{7}$ Increased concentrations of sCD95 might thus give rise to autoimmunity by inappropriate survival of autoreactive cell populations-for example, immature B lymphocyte cell lines in peripheral lymph nodes. This mechanism is in line with the increased autoantibody production observed in the MRL-lpr/lpr mouse model and in its human counterpart, the genetic CD95 defect leading to the Canale-Smith syndrome. ${ }^{24}$ However, the genetic background of SLE is not identical with the monogenetic Canale-Smith syndrome. Other defects, such as apoptosis defects in B cells, inappropriately low clearance of apoptotic bodies, and increased production of B cell stimulating cytokines, such as interleukin 8 and interleukin 10, may contribute to increased production of autoantibodies in SLE. Increased sCD95 concentrations in SLE may also result from impaired clearance of apoptotic cell fragments. In this hypothesis, activation of lymphocytes leads to up regulation of CD95. Subsequently, the resulting activation-induced cell death of CD95 positive cells overloads the body's clearance capacity. $^{25} 26$

In conclusion, plasma concentrations of sCD95 are not increased in first degree relatives of patients with SLE. There is, however, an increase of sCD95 in patients with severe SLE, independent of concomitant factors such as disease flares and current immunosuppressive drugs.

MW van der Linden is supported by the Dutch Organisation for Scientific Research (NWO), grant No 904-61-110.

1 Arnett FC, Hamilton RG, Reveille JD, di Bias W, Harley JB, Reichlin M, et al. Genetic studies of Ro (SS-A) and La (SS-B) autoantibodies in families with primary Sjögren syndrome. Arthritis Rheum 1989;32:413-19.

2 Lippman SM, Arnett FC, Conley CL, Ness PM, Meyers DA, Bias WB. Genetic factors predisposing to autoimmune diseases. Am J Med 1982;73:827-40.

3 Georgescu L, Vakkalanka RK, Elkon KB, Crow MK. Interleukin-10 promotes activation-induced cell death of SLE lymphocytes mediated by Fas ligand. J Clin Invest 1997;100:2622-33.

4 Arnett FC, Reveille JD. Genetics of systemic lupus erythematosus [review]. Rheum Dis Clin North Am 1992; 18:865-92.

5 Freedman BI, Wilson CH, Spray BJ, Tuttle AB, Olorenshaw IM, Kammer GM. Familial clustering of end-stage renal disease in blacks with lupus nephritis. Am J Kidney Dis 1997;29:729-32

6 Utz PJ, Hottelet M, Schur PH, Anderson P. Proteins phosphorylated during stress-induced apoptosis are common targets for autoantibody production in patients with systemic lupus erythematosus. J Exp Med 1997;185:84354.

7 Cheng J, Zhou T, Liu C, Shapiro JP, Brauer MJ, Kiefer MC, et al. Protection from Fas-mediated apoptosis by a soluble
form of the Fas molecule. Science 1994;263:1759-62.

8 Chan OT, Madaio MP, Shlomchik MJ. The central and multiple roles of B cells in lupus pathogenesis [review].
Immunol Rev 1999;169:107-21.

9 Papoff G, Cascino I, Eramo A, Starace G, Lynch DH, Ruberti G. An N-terminal domain shared by Fas/Apo-1 
(CD95) soluble variants prevents cell death in vitro. J

Immunol 1996;156:4622-30.
10 Cascino I, Fiucci G, Papoff G, Ruberti G. Three functional soluble forms of the human apoptosis-inducing Fas molecule are produced by alternative splicing. J Immuno 1995;154:2706-13.

11 van Lopik T, Bijl M, Hart M, Boeije L, Gesner T, Creasy AA, et al. Patients with systemic lupus erythematosus with high plasma levels of sFas risk relapse. J Rheumatol 1999; 26:60-7.

12 Tan EM, Cohen AS, Fries JF, Masi AT, McShane DJ, Rothfield NF, et al. The 1982 revised criteria for the classification of systemic lupus erythematosus. Arthritis Rheum, 1982;25:1271-7.

13 Gladman D, Ginzler E, Goldsmith C, Fortin P, Liang M, Urowitz $\mathrm{M}$, et al. The development and initial validation of the Systemic Lupus International Collaborating Clinics/ American College of Rheumatology Damage Index for sysAmerican College of Rheumatology Damage Index for systemic

14 Bombardier C, Gladman DD, Urowitz MB, Caron D, Chang $\mathrm{CH}$, Committee on prognosis studies in SLE. Derivation of the SLEDAI. A disease activity index for lupus patients. The Committee on Prognosis Studies in SLE. Arthritis Rheum 1992;35:630-40.

15 Bijl M, van Lopik Th, Limburg PC, Spronk PE, Jaegers SMHJ, Aarden LA, et al. Do elevated levels of serumsoluble Fas contribute to the persistence of activated lymphocytes in systemic lupus erythematosus? J Autoimmun 1998;11:457-63.

16 Al-Maini MH, Mountz JD, Al-Mohri AH, El-Ageb EM, Al-Riyami BM, Svenson KL, et al. Serum levels of soluble Fas correlate with indices of organ damage in systemic lupus erythematosus. Lupus 2000;9:132-9.

17 Tokano Y, Miyake S, Kayagaki N, Nozawa K, Morimoto S, Azuma M, et al. Soluble Fas molecule in the serum of patients with systemic lupus erythematosus. J Clin Immunol 1996;16:261-5.
18 Rose LM, Latchman DS, Isenberg DA. Elevated soluble fas production in SLE correlates with HLA status not with disease activity. Lupus 1997;6:717-22.

19 Goel N, Ulrich DT, St Clair EW, Fleming JA, Lynch DH, Seldin MF. Lack of correlation between serum soluble Fas/ APO-1 levels and autoimmune disease [see comments]. Arthritis Rheum 1995;38:1738-43.

20 Knipping E, Krammer PH, Onel KB, Lehman TJ, Mysler E, Elkon KB. Levels of soluble Fas/APO-1/CD95 in systemic lupus erythematosus and juvenile rheumatoid arthritis [see comments]. Arthritis Rheum 1995;38:1735-7.

21 Mountz JD, Zhou T, Cheng J. Use of sensitive assays to detect soluble $\mathrm{Fas}$ in patients with systemic lupus erythematosus: comment on the article by Knipping et al and the article by Goel et al [letter; comment]. Arthritis Rheum 1996;39:1611-12.

22 Ginzler EM, Diamond HS, Weiner M, Schlesinger M, Fries $\mathrm{JF}$, Wasner C, et al. A multicenter study of outcome in systemic lupus erythematosus. I. Entry variables as predictors of prognosis. Arthritis Rheum 1982;25:601-11

23 Aupeix K, Hugel B, Martin T, Bischoff P, Lill H, Pasquali $\mathrm{JL}$, et al. The significance of shed membrane particles during programmed cell death in vitro, and in vivo, in HIV-1 infection. J Clin Invest 1997;99:1546-54.

24 Drappa J, Vaishnaw AK, Sullivan KE, Chu JL, Elkon KB. Fas gene mutations in the Canale-Smith syndrome, an inherited lymphoproliferative disorder associated with autoimmunity [see comments]. N Engl J Med 1996;335: 1643-9.

25 Elkon KB. Apoptosis in SLE-too little or too much? [review]. Clin Exp Rheumatol 1994;12:553-9.

26 Huggins ML, Todd I, Cavers MA, Pavuluri SR, Tighe PJ, Powell RJ. Antibodies from systemic lupus erythematosus (SLE) sera define differential release of autoantigens from cell lines undergoing apoptosis. Clin Exp Immunol 1999;118:322-8. 